\title{
Cancer mortality in an international cohort of reinforced plastics workers exposed to styrene: a reanalysis
}

\author{
Dana Loomis, ${ }^{1,2}$ Neela Guha, ${ }^{1}$ Manolis Kogevinas, ${ }^{3,4,5,6}$ Vincenzo Fontana, ${ }^{7}$ \\ Valerio Gennaro, ${ }^{7}$ Henrik A Kolstad, ${ }^{8}$ Damien Martin McElvenny, ${ }^{9}$ Markku Sallmén, ${ }^{10}$ \\ Rodolfo Saracci ${ }^{1}$
}

\begin{abstract}
- Additional material is published online only. To view please visit the journal online (http://dx.doi.org/10.1136/ oemed-2018-105131).
\end{abstract}

For numbered affiliations see end of article.

\section{Correspondence to} Professor Dana Loomis, International Agency for Research on Cancer, Lyon 69008, France; loomisd@iarc.fr

Received 14 March 2018 Revised 15 March 2018 Accepted 18 March 2018 Published Online First 17 April 2018

\section{Check for updates}

(c) Author(s) (or their employer(s)) 2019. Re-use permitted under CC BY-NC. No commercial re-use. See rights and permissions. Published by BMJ.

To cite: Loomis $D$

Guha N, Kogevinas M

et al. Occup Environ Med 2019:76:157-162.

\section{ABSTRACT}

Objective To investigate the carcinogenicity of styrene by reanalysing data from a previous international cohort study of workers in the reinforced plastics industry. Methods Mortality from cancers of prior interest was analysed with more detailed consideration of exposureresponse relations and an updated classification of leukaemias and lymphomas in data from a previous international cohort study of 37021 reinforced plastics workers exposed to airborne styrene.

Results Increased mortality from non-Hodgkin's lymphoma (NHL) was associated with the mean level of exposure to styrene in air (relative risk (RR) 2.31, $95 \% \mathrm{Cl} 1.29$ to 4.12 per 100 ppm), but not with cumulative styrene exposure. Similar associations with mean exposure were observed for the oesophagus (RR $2.44,95 \% \mathrm{Cl} 1.11$ to 5.36 per $100 \mathrm{ppm}$ ) and pancreas (RR 1.89, 95\% Cl 1.17 to 3.09). Oesophageal cancer mortality was also associated with cumulative styrene exposure lagged 20 years (RR $1.16,95 \% \mathrm{Cl} 1.03$ to 1.31). No other cancer, including lung cancer, was associated with any indicator of styrene exposure. Conclusion This reanalysis does not substantially change the conclusions of the original study with respect to NHL or lung cancer but new evidence concerning cancers of the oesophagus and pancreas merits further investigation.

\section{INTRODUCTION}

Styrene is a common industrial chemical that is produced worldwide in large volumes and is used in making plastic products, foams, resins and synthetic rubber. ${ }^{1}$ Occupational exposure to styrene can occur in industries producing or using it, while the population at large may be exposed to styrene at lower concentrations as a component of air pollution and of cigarette smoke and as a food contaminant. ${ }^{2}$

Investigations into the potential carcinogenicity of styrene were prompted by reports in the 1970 s and 1980s of excess leukaemia and lymphoma among workers in styrene production and polymerisation and styrene-butadiene rubber manufacturing facilities. ${ }^{3-6}$ Following these initial reports, further epidemiological studies focusing on cancers of the haematolymphatic system were undertaken in those industries (eg, refs. $\left.{ }^{7-9}\right)$ and in the reinforced plastics industry, ${ }^{10-12}$ where styrene exposures were high

\section{Key messages}

What is already known about this subject?

- Styrene is classified as a possible carcinogen based on associations with leukaemia and lymphoma in previous studies.

- Recent studies suggest positive associations with several other cancers, including lung cancer.

What are the new findings?

- Among reinforced plastics workers, mortality from non-Hodgkin's lymphoma was associated with career mean styrene exposure, but not with cumulative styrene exposure.

- Cancer of the oesophagus was significantly associated with cumulative and mean styrene exposure.

- Cancer of the pancreas was significantly associated with mean styrene exposure.

- Mortality from myeloid leukaemia was not significantly associated with any measure of styrene exposure, nor was lung cancer mortality.

How might this impact on policy or clinical practice in the foreseeable future?

- The carcinogenicity of styrene merits further investigation taking into account these new findings.

and few other known or suspected carcinogens were believed to be present.

Based on observations of positive associations between exposure to styrene and diverse cancers of lymphatic and haematopoietic tissues in several of these epidemiological studies and on experimental findings, styrene was subsequently classified as 'possibly carcinogenic to humans' (group 2B) by the International Agency for Research on cancer ${ }^{2}$ and as 'reasonably anticipated to be a human carcinogen' in the US Report on Carcinogens. ${ }^{13}$

Subsequent to those evaluations, further analyses of several cohorts exposed to styrene have reported increased risks of other cancers, notably lung cancer. ${ }^{14-19}$ In addition, the understanding of the leukaemias and lymphomas has changed considerably, with multiple myeloma and the acute 
and chronic lymphoid leukaemias now classified as subtypes of non-Hodgkin's lymphoma (NHL). ${ }^{20}$

To investigate the extent to which leukaemia, NHL, as currently defined, and cancers of the lung and several other sites might be associated with occupational exposure to styrene, we reanalysed data from a large international cohort study of glass-reinforced plastics workers ${ }^{12}$ with a more detailed consideration of latency and exposure-response relations. The last analysis of this cohort published in 1994 showed a statistically significant trend in mortality from all lymphatic and haematopoietic cancers combined with increasing mean, but not cumulative, styrene exposure and non-significant increases in mortality from malignant lymphoma, as then defined, with both cumulative and mean styrene exposure. ${ }^{12}$

\section{METHODS}

\section{Study population}

In 1988, the International Agency for Research on Cancer (IARC) initiated a study of workers in the reinforced plastics industry in Denmark, Finland, Italy (two centres), Norway, Sweden and the UK (in the UK, two centres) to investigate associations between the risk of tumours of the lymphatic and haematopoietic systems and exposure to styrene. The study population and methods have been described elsewhere. ${ }^{12}$ Briefly, workers were enrolled from eight centres encompassing $>600$ plants. One cohort in the UK had been enumerated and analysed previously, ${ }^{9}$ and results from a separate analysis of the Danish cohort were published simultaneously with those of the full international study. ${ }^{21}$ In total, 40668 workers (34560 men and 6128 women) were included and followed for cancer mortality. The follow-up period averaged 13 years with the dates spanned varying among cohorts, from 1945 at the earliest to 1991 at the latest. In total, about $3 \%$ of the cohort was lost to follow-up ranging from $<1 \%$ in Finland to $7 \%$ in one UK centre.

Updated results for the Danish cohort and one British cohort based on extended follow-up have been published recently, ${ }^{16} 17$ and we investigated the possibility of updating the follow-up for the other six cohorts. However, this proved to be infeasible principally due to retirements of investigators and loss of records in several centres. In addition, new national privacy protection legislation prohibited the use of existing data from Norway, which had contributed $9 \%$ of person-time in the original cohort. Consequently, we reanalysed data from the cohort excluding Norway and did not add new mortality data from the two cohorts whose follow-up had been extended in order to avoid large variations in the time period of observation. Analysis files were reconstructed from the original data and errors were corrected in the process.

\section{Cancer mortality data}

The previous analysis of the cohort focused on cancers of lymphatic and haematopoietic tissues, with detailed data presented for all such cancers combined, leukaemias and malignant lymphomas, as defined in the 8th revision of the International Classification of Diseases (ICD). More limited analyses were reported for cancers of the lung, oesophagus, kidney and pancreas. ${ }^{12}$

To update the analysis, we regrouped ICD 8 and 9 codes from the original study to approximate the current WHO classification of the lymphomas and leukaemias, ${ }^{20}$ as we did not have access to original diagnostic records (online supplementary table S1). Codes for lymphosarcoma and reticulosarcoma (200), other malignant neoplasms of lymphoid and histiocytic tissue (202), chronic lymphoid leukaemia (204.1) and multiple myeloma (203) were aggregated under the heading of NHL; there were no deaths in the cohort from acute lymphoid leukaemia, which is also considered to be a subtype of NHL. Acute and chronic myeloid leukaemia (ICD 8/9 205.0 and 205.1, respectively) were combined for analysis because of small numbers. This grouping was done independent of knowledge about exposure status of any individuals in the cohort.

In addition, we conducted internal exposure-response analyses for the other specific cancers considered in the previous analyses and for cancers of the bladder and prostate, which showed positive associations in several recent studies ${ }^{14-19} 22$ and had at least 10 deaths among exposed workers.

\section{Exposure assessment}

The study plants, most of which were small, produced a variety of reinforced plastic products including boats, tanks, containers, panels and small pieces, such as helmets, by laminating fibres with resins containing styrene. Workers were assigned to mutually exclusive groups based on their longest-held jobs. Laminators, production workers with mixed tasks or in small plants with no fixed job titles and workers who regularly entered areas where styrene was handled but were not involved in manual lamination were classified as exposed to styrene. Other manual and clerical personnel who worked in the industry but were not regularly exposed to styrene were classified as unexposed. The duration of exposure was estimated as the time employed in exposed jobs, which may have begun after the start of employment. Information on job titles and tasks was not available in Denmark, so all workers in that subcohort were assigned to an unspecified job category presumed to involve exposure to styrene.

Quantitative exposure to styrene was estimated from approximately 11600 personal measurements of styrene in air in the years 1970-1990. In those cases when multiple measurements were available for a worker, they were combined to estimate the timeweighted average. Mean styrene concentrations were estimated according to country, job, product and time period and entered into a job-exposure matrix (JEM), which was then linked to full individual work histories. An analysis of about 18000 measurements of mandelic and phenoglyoxylic acid, the main styrene metabolites in urine, supported the development of the JEM. ${ }^{23}$ Because exposure data for years before 1970 were only available for Denmark, exposures in other countries during earlier years were estimated by extrapolation. ${ }^{12}$ In those countries, the average styrene concentration was assumed to have been 200 ppm, as observed in Denmark, until 1965 and then to decline linearly to the arithmetic mean of the earliest measurements in each country.

\section{Data analysis}

We analysed associations of mortality from the selected cancers with indicators of exposure to styrene using the ungrouped form of Poisson regression, equivalent to the discrete-time hazard model $^{2425}$ to estimate adjusted rate ratios (RRs) and likelihood-based 95\% CIs. Follow-up time was treated as the time axis, with each observation representing one person-year of experience or a fraction thereof in the case of censoring during the year. For each type of cancer, we first evaluated demographic and occupational predictors including age at risk, calendar time, sex, country, length of follow-up and time since first exposure. to develop a base model that best fit the mortality data as assessed by the Akaike information criterion (AIC). Age, calendar time, sex and country were entered in categorical form, while length of follow-up and time since first exposure were treated as continuous linear variables. We evaluated the effect of each covariate on the association of cancer mortality with styrene exposure and any that appreciably changed the RR were retained. Different covariates could thus be 
selected according to the outcome, resulting in a final model that estimated parameters for indicators of exposure to styrene adjusted for those factors.

The exposure indicators evaluated included employment in exposed jobs, employment as a laminator (the job with the highest average exposure to styrene), duration in exposed jobs, cumulative styrene exposure (ppm-years) and mean styrene concentration (ppm) in exposed jobs. Cumulative and mean styrene exposure were entered as continuous variables assuming a model of form $\ln (\mathrm{RR})=\beta \mathrm{X}+\gamma P$ in which the natural $\log$ of the RR is linearly related to the level of styrene exposure, $X$, and a vector of other demographic and occupational predictor variables, P. To investigate potential latency effects, we evaluated cumulative and mean exposure lagged by $0,5,10$ and 20 years for lymphohaematopoietic cancers and by 0,10 and 20 years for other cancers.

To further investigate the shape of the exposure-response function for lung cancer, which had the largest number of deaths, we conducted additional analyses in which exposure was smoothed with penalised splines. The fit of alternative models was assessed using the likelihood ratio $\chi^{2}$ for the exposure terms.

Analyses using log-linear models were performed in Stata and models using smoothed terms were fit in R. ${ }^{26}$

\section{RESULTS}

Descriptive data for the full cohort, including Norway, have already been published ${ }^{12}$ and have not substantially changed. After reconstructing the analysis files, correcting errors and excluding data from Norway, this reanalysis included 37021 workers, who contributed approximately 506459 person-years of follow-up experience, during which 2351 had died. In the cohort with Norway excluded, the mean duration of employment was 3.1 years and workers spent an average of 2.2 years in jobs exposed to styrene. The arithmetic mean concentration of styrene during employment in these jobs was approximately $63 \mathrm{ppm}$, resulting in an arithmetic mean cumulative exposure of about 158 ppm-years per worker (table 1). Exposed and unexposed workers within the cohort had similar mortality for all causes and all cancer (RR 1.01, $95 \%$ CI 0.89 to 1.14 and $1.01,95 \% \mathrm{CI} 0.81$ to 1.17 , respectively) (online supplementary table S2).

Mortality rates for the cancers of prior interest were not significantly increased among all workers who held jobs involving exposure to styrene compared with unexposed workers (table 2). RRs were 3.50 (95\% CI 0.46 to 26.82 ) and 1.85 (95\% CI 0.81 to 6.15 ) for oesophageal cancer and prostate cancer, respectively, and near or below unity for all other cancers, including NHL and myeloid leukaemia.

Among laminators, RRs were elevated for cancer of the oesophagus (RR 2.71, 95\% CI 1.00 to 7.37 ), pancreas (RR $1.18,95 \% \mathrm{CI}$ 0.53 to 2.61 ) and prostate (RR $1.85,95 \% \mathrm{CI} 0.64$ to 5.36 ).

Mortality from NHL (RR 1.40, 95\% CI 0.51 to 3.79) and cancer of the pancreas (RR 2.12, 95\% CI 0.93 to 4.38) was increased among workers employed 2 to $<5$ years in exposed jobs relative to workers exposed for $<2$ years (table 2), but no consistent increase in mortality from those cancers was observed among workers exposed $>5$ years. Oesophageal cancer mortality was increased in workers exposed for $\geq 2$ years (RR $1.80,95 \%$ CI 0.62 to 45.22 ), but there were too few deaths for analysis of longer exposure duration. Mortality from cancers of the lung (RR $1.14,95 \% \mathrm{CI} 0.80$ to 1.62) and prostate (RR 1.35, 95\% CI 0.57 to 3.16 ) was increased only among workers employed $\geq 5$ years. For lung cancer, which had the largest number of deaths (231), we also considered longer exposure durations of 5 to $<10,10$ to $<20$ and $\geq 20$ years; the RRs in these categories were 1.02 (95\% CI 0.65 to 1.60), 1.29 (95\% CI
Table 1 International Agency for Research on Cancer cohort of reinforced plastics workers exposed to styrene, 1945-1991, cohort characteristics

\begin{tabular}{|c|c|c|c|}
\hline & $\mathbf{N}$ & $\% *$ & Person-years \\
\hline All workers & 37021 & 100 & 506459 \\
\hline Men & 31692 & 85 & 428006 \\
\hline Women & 5692 & 15 & 78453 \\
\hline Exposed job & 31803 & 85 & 407459 \\
\hline Laminators & 8946 & 24 & 132062 \\
\hline Unexposed job & 3797 & 11 & 66412 \\
\hline Unknown job & 1833 & 5 & 32705 \\
\hline \multicolumn{4}{|l|}{ Employment duration (years) } \\
\hline$<2$ & 22865 & 62 & 307521 \\
\hline 2 to $<5$ & 5583 & 15 & 82698 \\
\hline$\geq 5$ & 7086 & 19 & 95895 \\
\hline Unknown & 1487 & 4 & 20345 \\
\hline \multicolumn{4}{|l|}{ Exposure duration (years) } \\
\hline$<2$ & 24715 & 67 & 339328 \\
\hline 2 to $<5$ & 4593 & 12 & 64646 \\
\hline$\geq 5 y$ & 5075 & 14 & 61514 \\
\hline \multirow[t]{2}{*}{ Unknown } & 2638 & 7 & 40971 \\
\hline & Mean & Range & \\
\hline Mean employment duration (years) & 3.1 & $<0.01-62.0$ & \\
\hline Mean exposure duration (years) & 2.2 & $0-33.5$ & \\
\hline Mean length of follow-up (years) & 12.8 & $0-45.0$ & \\
\hline Mean styrene exposure (ppm) & 63.1 & $0-205.0$ & \\
\hline $\begin{array}{l}\text { Mean cumulative styrene exposure } \\
\text { (ppm-years) }\end{array}$ & 158.0 & $0-4543.1$ & \\
\hline
\end{tabular}

*Per cents may not add to 100 because of rounding.

0.77 to 2.15$)$ and 1.56 (95\% CI 0.49 to 4.97$)$, respectively. There were no significant trends in mortality from any cancer with the duration of exposure to styrene (table 2). For cancers of the kidney and bladder, the RRs for all of the exposure metrics considered were near unity or below.

We analysed exposure-response relationships of styrene with mortality from total NHL (including multiple myeloma), multiple myeloma, myeloid leukaemia and lung cancer, which were of prior interest, and with cancers of the oesophagus, pancreas and prostate, as they had adequate numbers for analysis and indications of associations with employment in exposed jobs and exposure duration.

For NHL, the RR was 1.02 or 1.03 per 100 ppm-years of cumulative exposure to styrene for lag periods of 0,5 and 10 years and was not statistically significant (table 3). However, NHL mortality was significantly associated with mean styrene concentration in exposed jobs (RR 2.31, 95\% CI 1.29 to 4.12 per $100 \mathrm{ppm}$ with a 0 -year lag). Multiple myeloma was non-significantly associated with cumulative styrene exposure with a 10-year lag and with mean styrene exposure for all lag intervals (table 3). Myeloid leukaemia was not associated with cumulative styrene exposure, while RRs were non-significantly increased with increasing mean exposure (table 3 ).

Lung cancer mortality was not associated with any quantitative measure of styrene exposure (table 4). Mortality from oesophageal cancer was significantly associated with cumulative styrene and mean styrene exposure lagged 20 years (RRs $1.16,95 \% \mathrm{CI}$ 1.03 to 1.31 per 100 ppm-years and RR 3.36, 95\% CI 1.74 to 6.49 per $100 \mathrm{ppm}$, respectively). Mortality from cancer of the pancreas increased significantly with unlagged mean styrene exposure (RR $1.89,95 \%$ CI 1.17 to 3.06 per $100 \mathrm{ppm}$ ), but not with cumulative 
Table 2 Cancer mortality by job and exposure duration, International Agency for Research on Cancer cohort of reinforced plastics workers exposed to styrene, 1945-1991

\begin{tabular}{|c|c|c|c|c|c|c|c|c|c|c|c|c|c|c|c|c|c|}
\hline \multirow{2}{*}{$\begin{array}{l}\text { Cancer (number } \\
\text { of deaths) }\end{array}$} & \multicolumn{2}{|c|}{$\begin{array}{l}\text { Unexposed } \\
\text { jobs* }\end{array}$} & \multicolumn{3}{|c|}{ Exposed jobs } & \multicolumn{3}{|c|}{ Laminators } & \multicolumn{2}{|c|}{$\begin{array}{l}\text { Exposed } \\
<2 \text { years }\end{array}$} & \multicolumn{3}{|c|}{ Exposed $2<5$ years } & \multicolumn{3}{|c|}{ Exposed $\geq 5$ years } & \multirow[t]{2}{*}{ P-trendt } \\
\hline & $\mathrm{N}$ & $\mathbf{R R}$ & $\mathrm{N}$ & RR‡ & $95 \% \mathrm{Cl}$ & $\mathrm{N}$ & RR & $95 \% \mathrm{Cl}$ & $\mathrm{N}$ & RR & $\mathrm{N}$ & $\mathbf{R R}$ & $95 \% \mathrm{Cl}$ & $\mathrm{N}$ & $\mathbf{R R}$ & $95 \% \mathrm{Cl}$ & \\
\hline NHL $(29) \S$ & 5 & 1.00 & 22 & 1.01 & 0.37 to 2.74 & 6 & 0.98 & 0.40 to 2.42 & 17 & 1.00 & 5 & 1.40 & 0.51 to 3.79 & 5 & 0.92 & 0.34 to 2.54 & 0.78 \\
\hline $\begin{array}{l}\text { Multiple myeloma } \\
\text { (8) }\end{array}$ & 2 & 1.00 & 8 & 1.05 & 0.20 to 5.37 & 0 & 0 & - & 7 & 1.00 & 39 & 0.77 & 0.20 to 3.00 & 1 & - & - & 0.23 \\
\hline $\begin{array}{l}\text { Myeloid leukaema } \\
(15)^{* *}\end{array}$ & 2 & 1.00 & 12 & 0.57 & 0.09 to 3.49 & 1 & 0.19 & 0.01 to 3.49 & 10 & 1.00 & $4 ף$ & 0.53 & 0.14 to 1.94 & 3 & - & - & 0.53 \\
\hline Lung (231) & 48 & 1.00 & 159 & 0.85 & 0.57 to 1.19 & 49 & 0.88 & 0.62 to 1.25 & 144 & 1.00 & 26 & 0.94 & 0.62 to 1.42 & 42 & 1.14 & 0.80 to 1.62 & 0.43 \\
\hline Oesophagus (16) & 1 & 1.00 & 15 & 3.50 & 0.46 to 26.82 & 7 & 2.71 & 1.00 to 7.37 & 8 & 1.00 & $6 ף$ & 1.80 & 0.62 to 5.22 & 4 & - & - & 0.20 \\
\hline Pancreas (35) & 7 & 1.00 & 27 & 1.06 & 0.46 to 2.46 & 8 & 1.18 & 0.53 to 2.61 & 19 & 1.00 & 8 & 2.12 & 0.93 to 4.38 & 7 & 1.33 & 0.56 to 3.19 & 0.65 \\
\hline Bladder (25) & 3 & 1.00 & 21 & 0.92 & 0.22 to 3.80 & 3 & 0.88 & 0.22 to 3.50 & 18 & 1.00 & 3 & 0.72 & 0.21 to 2.46 & 3 & 0.54 & 0.15 to 1.94 & 0.57 \\
\hline Kidney (13) & 2 & 1.00 & 9 & 0.83 & 0.18 to 3.99 & 3 & 0.88 & 0.21 to 3.71 & 7 & 1.00 & $4 ף$ & 1.08 & 0.31 to 3.78 & 2 & - & - & 0.90 \\
\hline Prostate (33) & 5 & 1.00 & 27 & 1.85 & 0.64 to 5.36 & 5 & 1.36 & 0.47 to 3.89 & 22 & 1.00 & 4 & 0.92 & 0.32 to 2.70 & 7 & 1.35 & 0.57 to 3.16 & 0.77 \\
\hline
\end{tabular}

*Missing and unknown jobs excluded.

tP for continuous linear variable.

¥RRs adjusted as follows: NHL, lung cancer, bladder cancer: age, calendar decade, country, sex; multiple myeloma: age, calendar decade, sex; myeloid leukaemia: age, sex, country; kidney cancer: age, calendar decade, sex; prostate cancer: age, country; pancreatic cancer, oesophageal cancer: age.

§Includes multiple myeloma.

१Exposure duration $\geq 2$ years.

**Includes acute and chronic myeloid leukaemia.

$\mathrm{NHL}$, non-Hodgkin's lymphoma; RR, rate ratio.

exposure. Mortality from cancer of the prostate showed a similar pattern of a non-significant increase with higher unlagged mean exposure, but no association with cumulative exposure (table 4).

For lung cancer mortality and cumulative exposure to styrene, we also investigated the shape of the exposure-response function using non-parametric spline models. These models did not fit the data better, as assessed by AIC, than parametric models with cumulative exposure entered as a linear term, however (illustrative data shown in online supplementary figure S1).

We conducted additional analyses to assess the effects on the results of uncertainties in estimating exposure to styrene. To gauge potential misclassification due to the lack of detailed occupational histories for workers in Denmark, we repeated the principal analyses excluding that subcohort. To evaluate potential bias due to the lack of quantitative exposure data for years before 1970 in countries other than Denmark, we performed two additional exposureresponse analyses. One used alternative exposure estimates based on an assumption that styrene concentrations in the period when no data were available were equal to the earliest measured concentrations in each country ${ }^{12}$ and another included only workers first exposed after 1970. Among the latter group of workers first exposed in later years, lung cancer mortality was significantly associated with cumulative styrene exposure (RR $1.11,95 \%$ CI 1.02 to 1.20 ) and non-significantly increased with mean exposure (RR 1.26, 95\% CI 0.76 to 2.07). None of the other analyses gave results materially different from those based on the full cohort or the primary exposure model for any cancer, although the exclusions reduced the precision of most risk estimates (online supplementary table S3).

\section{DISCUSSION}

In this reanalysis of an international cohort of workers exposed to styrene in the glass-reinforced plastics industry, mortality from NHL and cancers of the oesophagus, pancreas and prostate showed associations with the employment in exposed jobs or the duration of such employment, but effect estimates were imprecise and trends with duration were not statistically significant.

Increased mortality from lympohaematopoietic cancers, including NHL, has also been reported in several industrial cohorts $^{3-11}$ as well as a previous analysis of this cohort which showed associations with the metrics of time since first exposure and average level of exposure to styrene, but not with duration of

Table 3 Mortality from lymphohaematopoietic cancers and estimated exposure to styrene, International Agency for Research on Cancer cohort of reinforced plastics workers exposed to styrene, 1945-1991

\begin{tabular}{|c|c|c|c|c|c|c|c|c|c|}
\hline & \multicolumn{3}{|c|}{ NHL $(n=24)$} & \multicolumn{3}{|c|}{ Multiple myeloma $(n=8)$} & \multicolumn{3}{|c|}{ Myeloid leukaemia* $(n=15)$} \\
\hline & RRt & $95 \% \mathrm{Cl} \dagger$ & AIC & RR & $95 \% \mathrm{Cl}$ & AIC & RR & $95 \% \mathrm{Cl}$ & AIC \\
\hline \multicolumn{10}{|c|}{ Cumulative styrene exposure (100 ppm-years) } \\
\hline 0-year lag & 1.02 & 0.94 to 1.10 & 488.2 & 0.82 & 0.54 to 1.26 & 179.7 & 0.90 & 0.73 to 1.10 & 314.6 \\
\hline 5-year lag $\dagger$ & 1.02 & 0.94 to 1.11 & 488.2 & 0.87 & 0.59 to 1.27 & 180.3 & 0.91 & 0.73 to 1.12 & 315.1 \\
\hline 10-year lag & 1.03 & 0.94 to 1.12 & 488.1 & 1.69 & 0.30 to 1.62 & 179.5 & 0.88 & 0.66 to 1.17 & 315.0 \\
\hline \multicolumn{10}{|c|}{ Mean styrene exposure (100 ppm) } \\
\hline 0-year lag & 2.31 & 1.29 to 4.12 & 480.3 & 1.86 & 0.71 to 4.86 & 179.6 & 0.92 & 0.37 to 2.32 & 316.1 \\
\hline 5 -year lag $\dagger$ & 2.29 & 1.33 to 3.93 & 479.6 & 2.25 & 0.92 to 5.48 & 178.1 & 1.34 & 0.61 to 2.94 & 315.6 \\
\hline 10-year lag & 1.78 & 1.05 to 3.02 & 484.2 & 1.31 & 0.48 to 3.58 & 180.9 & 1.50 & 0.71 to 3.17 & 315.1 \\
\hline
\end{tabular}

*Includes acute myeloid leukaemia and chronic myeloid leukaemia.

tRR per 100 ppm-year or 100 ppm; RRs adjusted as follows: NHL, multiple myeloma, age, calendar decade, sex; myeloid leukaemia, age, calendar year, sex, country. AIC, Akaike information criterion; NHL, non-Hodgkin's lymphoma; RR, rate ratio. 
Table 4 Cancer mortality and estimated exposure to styrene, International Agency for Research on Cancer cohort of reinforced plastics workers exposed to styrene, 1945-1991

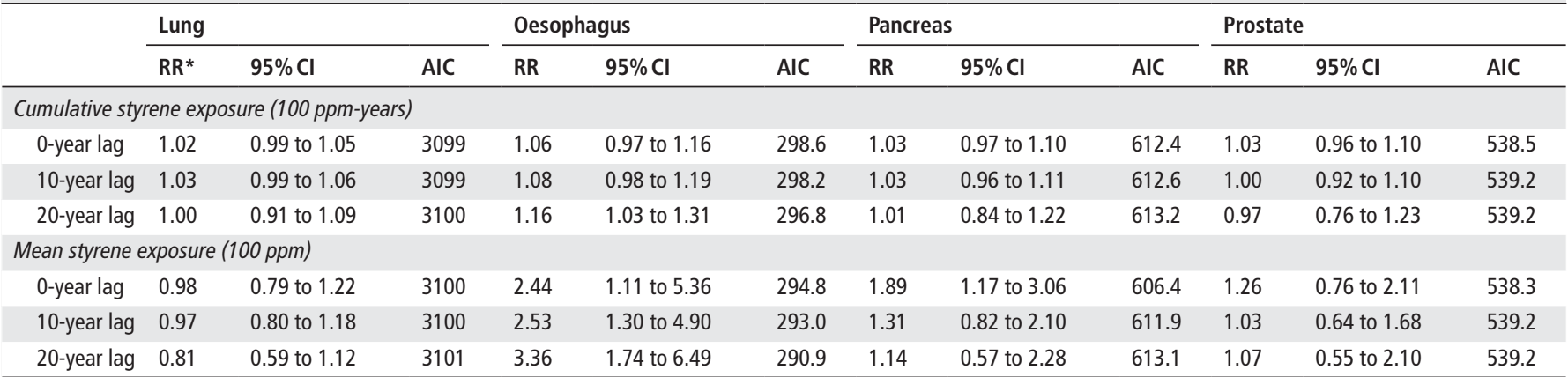

*RR per 100 ppm-year or 100 ppm. RRs adjusted as follows: NHL, age, calendar decade, sex; lung cancer, age, sex, country; oesophageal cancer, pancreatic cancer: age; prostate cancer: age, country.

AIC, Akaike information criterion; NHL, non-Hodgkin's lymphoma; RR, rate ratio.

exposure or cumulative exposure. ${ }^{12}$ However, these prior studies used various definitions of NHL that have been superseded by the current WHO definition. In this reanalysis, NHL was defined by regrouping ICD codes for lymphomas and leukaemias from the original study following the current WHO classification, which now includes multiple myeloma and acute and chronic lymphatic leukaemia. ${ }^{20}$ We did not have the detailed information needed to identify B-cell and T-cell lymphomas or other NHL subtypes that did not have codes in the 8th and 9th revisions of the ICD. This regrouping yielded associations of styrene exposure and NHL mortality that were essentially similar to those in the original analysis of the cohort. ${ }^{12}$

We found statistically significant associations of oesophageal cancer with cumulative and mean styrene exposure and of pancreatic cancer with mean styrene exposure that were not seen in the less detailed exposure-response analysis in the previous paper. ${ }^{12}$

No clear increase in mortality from lung or bladder cancer with exposure to styrene was observed in this reanalysis or in the original analysis, ${ }^{12}$ but we did find increased lung cancer risk among workers employed $>10$ years and among those hired after 1970 . Excess risk of lung and bladder cancers has been reported in other studies, 714151922 including in updated data for components of this cohort from Denmark and the UK. ${ }^{16}{ }^{17}$ Given that these reports were based on extended follow-up of cohorts enumerated around the same time as the one we studied, it is possible that longer follow-up is needed to observe any increase in lung cancer mortality.

Inconsistencies in reported results between publications may be due to several factors. Some previous studies may have been underpowered to detect an effect as they examined cancer mortality in industries where levels of exposure to styrene are fairly low. Furthermore, co-exposures to known or suspected carcinogens may have occurred, resulting in spurious findings. For example, workers in the styrene-butadiene rubber industry may have significant exposures to 1,3-butadiene, while workers involved in styrene production and polymerisation may be exposed to diverse chemicals, including benzene. ${ }^{57}$ Benzene and 1,3-butadiene are recognised causes of leukaemia, and positive associations with NHL have been seen in some studies. ${ }^{27}$

A strength of this study is that it was based on observations of >37 000 workers, most of whom were exposed to styrene without significant exposures to other carcinogens. Acetone is the most frequent chemical co-exposure encountered in the reinforced plastics industry, ${ }^{28}$ but is not known or suspected to be carcinogenic. ${ }^{29}$ The presence of dichloromethane (arithmetic mean concentration $51 \mathrm{mg} / \mathrm{m}^{3}$ ) was reported in a study of Danish industries, including reinforced plastics, that used styrene in the period 1955-1988; perchloroethylene and trichloroethylene were also detected in a small number of samples, but the concentrations were very low. ${ }^{28}$ Styrene 7,8-oxide has been detected more recently in the air of reinforced-plastic manufacturing workshops, ${ }^{30}$ but no measurements were available for the facilities included in this study. Workers involved in the lamination process may also have been exposed to man-made fibres, including continuous glass filaments; although no data on exposure levels were available for the cohort, previous studies have not demonstrated a link with cancer. ${ }^{31}$

Moreover, several previous studies were unable to account for potential confounding by non-occupational risk factors, notably tobacco smoking, as no information was collected at the individual level and analyses were based on SMRs with the general population as a referent group. Although information on tobacco smoking and other personal risk factors was also lacking for our international cohort, concerns about potential confounding by non-occupational risk factors are reduced in our analyses with an internal referent group of unexposed or less exposed workers.

Other limitations of this study include the deletion of data from Norway, which modestly reduced precision for some estimates, the relatively short duration of employment in the industry and of follow-up (approximately 3 and 13 years, respectively, on average) and small numbers of deaths for some of the cancers of interest. Approximately $60 \%$ workers in our study were employed $<2$ years, reflecting the typical employment pattern in the industry. ${ }^{12}$ The observed tendency for several cancers to be associated with mean, but not cumulative styrene exposure may be related to the short duration of exposure for most workers, which would minimise contrast in cumulative exposure. Given the high proportion of short-term workers, healthy worker survivor bias could be a potential explanation for the observation that the risk estimates for NHL and cancers of the pancreas and prostate were higher in workers who were exposed to styrene $2-5$ years relative to those exposed for $\geq 5$ years.

It is also possible that some risk estimates were affected by exposure measurement error. Because all workers in Denmark were assigned to an unspecified job category presumed to involve exposure to styrene, up to one-fourth of the workers classified as styrene exposed may have actually been unexposed. However, analyses excluding Denmark gave similar results, so the impact of this potential source of error appears to have been minimal. It is also possible that heavily exposed short-term workers were excluded from the cohort because early payroll records (used to classify workers with respect to styrene exposure) were not available from all of the 660 plants for various reasons. ${ }^{12}$ The estimation 
of exposure before 1970 by extrapolating from measurements in Denmark is another potential source of information bias. If the actual exposures during that time were higher than the extrapolated estimates, then estimated RRs would be biased towards the null, while if they were lower, the RRs would be biased upwards.

\section{CONCLUSION}

This reanalysis using a modern definition of NHL and a more detailed analytical approach does not substantially change the conclusions of the original study with respect to the associations of NHL and lung cancer with exposure to styrene: NHL mortality was associated with mean career styrene exposure, while lung cancer was not associated with any indicator of styrene exposure in the full cohort. However, we found suggestive new evidence that increased mortality from cancer of the pancreas is associated with employment in exposed jobs and with average styrene concentration and that cancer of the oesophagus is associated with cumulative styrene exposure, as well as with these indicators. More information about the associations of these cancers with exposure to styrene would be valuable in light of the inconsistent results of other studies. A full update of cancer mortality in this cohort would be informative, but may not be feasible. New studies and updated analyses of populations occupationally and environmentally exposed to styrene are therefore warranted. Ideally, such studies would be based on cancer incidence data, which would improve the identification and classification of leukaemias and lymphomas.

\author{
Author affiliations \\ 'International Agency for Research on Cancer, Lyon, France \\ 2University of Nevada, Reno, Reno, Nevada, USA \\ ${ }^{3}$ ISGlobal, Barcelona, Spain \\ ${ }^{4}$ CIBER Epidemiologia y Salud Pública (CIBERESP), Barcelona, Spain \\ ${ }^{5}$ Universitat Pompeu Fabra (UPF), Barcelona, Spain \\ ${ }^{6}$ IMIM (Hospital del Mar Medical Research Institute), Barcelona, Spain \\ ${ }^{7}$ Policlinico San Martino, IRCCS Scientific Institute for Research and Care in \\ Oncology, Genova, Italy \\ ${ }^{8}$ Department of Occupational Medicine, Danish Ramazzini Centre, Aarhus University \\ Hospital, Aarhus, Denmark \\ ${ }_{9}$ Insitute of Occupational Medicine, Edinburgh, UK \\ ${ }^{10}$ Centre of Expertise for Health and Work Abili, Finnish Institute of Occupational \\ Health, Helsinki, Finland
}

\section{Correction notice Since this article first published online it has been updated to} open access.

Acknowledgements The authors gratefully acknowledge Tom Bellander, Marco Biocca, David Coggon, Claudia Galassi and Allan Astrup Jensen for their contributions to the original study and their reading of this paper.

Contributors DL and NG performed the data analysis and drafted the papers. All other authors contributed to data collection and critically reviewed the paper.

Funding The authors have not declared a specific grant for this research from any funding agency in the public, commercial or not-for-profit sectors.

Competing interests None declared.

Patient consent Not required.

Ethics approval This study was cleared by the IARC Ethics Committee as not presenting any potential ethical implications because it analyses deidentified historical data and reports aggregate statistical results.

Provenance and peer review Not commissioned; internally peer reviewed.

Open access This is an open access article distributed in accordance with the Creative Commons Attribution Non Commercial (CC BY-NC 4.0) license, which permits others to distribute, remix, adapt, build upon this work non-commercially, and license their derivative works on different terms, provided the original work is properly cited, appropriate credit is given, any changes made indicated, and the use is non-commercial. See: http://creativecommons.org/licenses/by-nc/4.0/.

\section{REFERENCES}

1 International Styrene Industry Forum (ISF). The styrene forum. 2017 http://www. styreneforum.org/index.html (accessed 24 Nov 2017).
2 International Agency for Research on Cancer. Some traditional herbal medicines, some mycotoxins, naphthalene and styrene. IARC Monographs on the Evaluation of Carcinogenic Risks to Humans. 2002:82.

3 Hodgson JT, Jones RD. Mortality of styrene production, polymerization and processing workers at a site in northwest England. Scand J Work Environ Health 1985;11:347-52.

4 Meinhardt TJ, Lemen RA, Crandall MS, et al. Environmental epidemiologic investigation of the styrene-butadiene rubber industry. Mortality patterns with discussion of the hematopoietic and lymphatic malignancies. Scand J Work Environ Health 1982:8:250-9.

5 Nicholson WJ, Selikoff IJ, Seidman H. Mortality experience of styrene-polystyrene polymerization workers. Initial findings. Scand J Work Environ Health 1978;4(Suppl 2):247-52.

6 Ott MG, Kolesar RC, Scharnweber HC, et al. A mortality survey of employees engaged in the development or manufacture of styrene-based products. J Occup Med 1980:22:445-60.

7 Bond GG, Bodner KM, Olsen GW, et al. Mortality among workers engaged in the development or manufacture of styrene-based products-an update. Scand J Work Environ Health 1992:18:145-54.

8 Matanoski GM, Santos-Burgoa C, Schwartz L. Mortality of a cohort of workers in the styrene-butadiene polymer manufacturing industry (1943-1982). Environ Health Perspect 1990;86:107-17

9 Coggon D, Osmond C, Pannett B, et al. Mortality of workers exposed to styrene in the manufacture of glass-reinforced plastics. Scand J Work Environ Health 1987;13:94-9.

10 Okun AH, Beaumont JJ, Meinhardt TJ, et al. Mortality patterns among styrene-exposed boatbuilders. Am J Ind Med 1985;8:193-205.

11 Wong 0. A cohort mortality study and a case-control study of workers potentially exposed to styrene in the reinforced plastics and composites industry. $\mathrm{Br} J$ Ind Med 1990;47:753-62.

12 Kogevinas M, Ferro G, Andersen A, et al. Cancer mortality in a historical cohort study of workers exposed to styrene. Scand J Work Environ Health 1994;20:251-61.

13 National Toxicology Program (NTP). 12th report on carcinogens. Rep carcinog 2011;12.

14 Sathiakumar N, Delzell E. A follow-up study of mortality among women in the North American synthetic rubber industry. J Occup Environ Med 2009:51:1314-25.

15 Sathiakumar N, Brill I, Delzell E. 1,3-butadiene, styrene and lung cancer among synthetic rubber industry workers. J Occup Environ Med 2009;51:1326-32.

16 Christensen MS, Hansen J, Ramlau-Hansen CH, et al. Cancer incidence in workers exposed to styrene in the danish-reinforced plastics industry, 1968-2012. Epidemiology 2017;28:300-10.

17 Coggon D, Ntani G, Harris EC, et al. Risk of cancer in workers exposed to styrene at eight British companies making glass-reinforced plastics. Occup Environ Med 2015:72:165-70.

18 Collins JJ, Bodner KM, Bus JS. Cancer mortality of workers exposed to styrene in the U.S. Reinforced plastics and composite industry. Epidemiology 2013;24:195-203.

19 Ruder AM, Meyers AR, Bertke SJ. Mortality among styrene-exposed workers in the reinforced plastic boatbuilding industry. Occup Environ Med 2016;73:97-102.

20 Swerdlow SH, Campo E, Harris NL, Jaffe ES, Pileri SA, et al. eds. WHO Classification of tumours of haematopoietic and lymphoid tissues. 4th edn. Lyon: IARC, 2017.

21 Kolstad HA, Lynge E, Olsen J, et al. Incidence of lymphohematopoietic malignancies among styrene-exposed workers of the reinforced plastics industry. Scand J Work Environ Health 1994;20:272-8.

22 Ruder AM, Bertke SJ. Cancer incidence among boat-building workers exposed to styrene. Am J Ind Med 2017;60:651-7.

23 Galassi C, Kogevinas M, Ferro G, et al. Biological monitoring of styrene in the reinforced plastics industry in Emilia Romagna, Italy. Int Arch Occup Environ Health 1993;65:89-95.

24 Loomis D, Richardson DB, Elliott L. Poisson regression analysis of ungrouped data. Occup Environ Med 2005;62:325-9.

25 Richardson DB. Discrete time hazards models for occupational and environmental cohort analyses. Occup Environ Med 2010;67:67-71.

26 R Development Core Team. R: a language and environment for statistical computing. Vienna, Austria: R Foundation for Statistical Computing, 2008.

27 International Agency for Research on Cancer (IARC). A review of human carcinogens, Part F: chemical agents and related occupations. IARC monographs on the evaluation of carcinogenic risks to humans. 2012:100F.

28 Jensen AA, Breum NO, Bacher J, et al. Occupational exposures to styrene in Denmark 1955-88. Am J Ind Med 1990;17:593-606.

29 Agency for Toxic Substances and Disease Registry (ATSDR). ToxFacts for acetone. https://www.atsdr.cdc.gov/toxfaqs/tf.asp?id=4\&tid=1\#bookmark06 (accessed 17 Dec 2017).

30 Serdar B, Tornero-Velez R, Echeverria D, et al. Predictors of occupational exposure to styrene and styrene-7,8-oxide in the reinforced plastics industry. Occup Environ Med 2006:63:707-12.

31 IARC (International Agency for Research on Cancer). Man-made vitreous fibres. IARC Monographs on the Evaluation of Carcinogenic Risks to Humans. 2002:81. 